DOI: $10.217672576-3903.100013$

\title{
Pharmacogenetics: Focus on Breast Cancer Treatment
}

\section{Md. Akbar Hossain ${ }^{1}$, Md. Abu Bakar Siddique ${ }^{1}$ and Reedwan Bin Zafar Auniq ${ }^{2 *}$}

${ }^{1}$ Department of Pharmacy, International Islamic University, Chittagong, Bangladesh, 4318

${ }^{2}$ Department of Chemistry, School of Science, Walailak University, Thailand.

${ }^{*}$ Corresponding author: Reedwan Bin Zafar Auniq, Department of Chemistry, School of Science, Walailak University, Thailand. Tel: 01991130571; E-mail: rbzauniq@gmail.com

Received: June 29, 2017; Accepted: July 04, 2017; Published: July 11, 2017

Citation: Hossain A, Siddique AB, Auniq RBZ (2017) Pharmacogenetics: Focus on Breast Cancer Treatment. J Neoplasm. 2:2.

\section{Introduction}

The success or failure of cancer treatment is based upon various factors including age, gender, stress, and disease type. The phenotypic changes results from variation in genetic makeup of the individuals and environmental factors, and use of drugs [1]. Further, these multiple variables are responsible for therapeutic and prognosis differences in patients and development of unwanted adverse side effects. This situation can be avoided by developing personalized medicine which can enhance benefits of treatment in individuals with fewer or no side effects [2]. Biological status, pathology, and genetic factors can be taken into consideration for the development of personalized treatment regimens $[3,4]$. Several natural compounds have already tested successfully for their potential anticancer activity and are in advanced studies. They have the advantage of lower treatment associated toxicities and better patient compliance $[5,6]$.

Breast cancer remains the second most lethal cancer in women, responsible significant deaths per year worldwide, and the disease affects so many women in their prime. The lethality of breast cancer can be because of its prominent heterogeneity $[7,8]$. Particularly in the Asian countries the cancer risk is more because of lack of awareness on treatment and diagnosis. By the time it is detected, the women are with more advanced disease state which is difficult to treat [9]. While optimizing and enhancing the strategies for existing therapies in the form drug targeting, sustained release dosage forms and enhanced drug delivery techniques [10-12], it is important to develop new and tolerable therapies in the $21^{\text {st }}$ century $[13,14]$. One of the latest and promising areas to address the cancer therapy is pharmacogenomics. Currently we can see significant advances and ongoing effort around the world in this context. Pharmacogenomics is the study of genetic variations in the individuals that can be employed to predict the drug therapeutic response, prognosis or toxicity [15].

Breast cancer is a disease in which malignant cells are formed in the tissues of the breast. During the growth of tumor, multiple mutations occur in cancer cells due to the adverse conditions they face and their micro environment interactions and make the disease complicated and hard to treat [16-18]. Drug-metabolizing enzymes, drug transporters and drug targets are the pivotal factors mediating the drug efficacy and bioavailability in the patient. But the gene variation in these enzymes are altering the pharmacokinetics and pharmacodynamics of the anti-cancer drugs and so the therapeutic outcome [19]. To address this issue, we need to analyze events at cellular, molecular, genetic and pathological levels. If we can apply the principles of pharmacogenomics in breast cancer treatment, it will enable us to give the treatment to match the pharmacological and genetic profile of the tumor in patients.

\section{Gene polymorphisms: Altered efficacy or toxicity}

After the administration of drugs into the patients, they undergo modifications and changed into their metabolites or active forms. These drug modifications are mostly carried out in the liver by hepatic metabolizing enzymes known as cytochrome P 450 enzymes (CYPs). One of the enzymes is CYP2D6 which is responsible for modification of tamoxifen into its prominent and antiestrogenic endoxifen. CYP2D6 metabolizing enzyme is highly polymorphic and is present in 46 variant forms. Some of the variants are nonfunctional. The nonfunctional form of the enzyme causes the accumulation of Tamoxifen in the patients and the therapy is not efficient. Moreover these inherited variations in the activity of CYP2D6 alters its tamoxifen metabolizing activity and changes the metabolite serum concentration and bioavailability [20].

Metabolizing enzymes' polymorphisms not only affects the therapeutic outcome but also alters the drug associated toxicity. Irinotecan is a topoisomerase I inhibitor used in metastatic colorectal cancer, non-small-cell lung cancer, and breast cancers. Irinotecan is a pro drug and should be converted to its active metabolite, $\mathrm{SN}-38$, in the liver. Further SN-38 is metabolized by UGT1A1 enzyme for further excretion. Polymorphisms in the UGT1A1 gene play important role in toxicity [21,22]. According to the FDA, patients with UGT1A1*28 genotype have risk factor for severe neutropenia or severe hematological toxicities.

Certain pattern of genomic variations is observed based upon the race and ethnicity. It was shown that toxicities associated with Cyclophosphamide (CPA) are linked with race differences. African Americans are more prone to toxic side 
effects with the CPA treatment. CPA is a nitrogen mustard alkylating agent from the oxazophorines group and is used in the breast cancer treatment [23]. Cyclophosphamide attaches the alkyl group to the guanine base of DNA, at the number 7 nitrogen atom of the imidazole ring and inhibits cancer cell growth. CPA is metabolized by CYP3A4 to toxic metabolite in some patients and causes severe nausea and vomiting [24]. CYP3A4 has demonstrated 20 -fold inter patient variability.

The phosphatidylinositol 3 kinase pathways (PI3Kinase pathway) are responsible for increased cancer cell proliferation and survival. Being a tumor suppressor gene, PTEN inactivation results in the accumulation of PI3P, and activation of a serine/threonine kinase [25]. Activation of Akt by PI3P modulates the activity of a variety of downstream proteins including BAD, Mdm2, p27, and FOXO transcription factors that are associated with increased cancer cell proliferation and survival. In a recent study, researchers have tested 72 primary breast cancer tissues and showed that 5 of them showed mutations in PTEN gene at exon 5. And also Patients with PTEN-deficient breast cancers developed resistance to treatment and displayed poor prognosis with trastuzumab-based therapy [26].

$A B C$ family of proteins belongs to the category of drug transporters expressed on cell surface. They are observed at epithelial barriers such as intestinal epithelial cells, hepatocytes, renal tubular cells, the blood-brain barrier, and cancer cells. They transport the drug out of the cells and prevent drug accumulation inside the cell. This can result in decreased drug efficiency. Abnormalities in the genes encoding the $A B C$ transporters also lead to diseases. $A B C 11$ wild type gene expression is very high in breast cancer cells and this condition decreases intracellular drug concentrations [27]. Till now more than 10 non-synonymous single nucleotide polymorphisms (SNPs) have been reported in the human ABCC11 gene [28]. ABCC11 gene is also responsible for the development of resistance in 5-FU (5-Fluoro Uracil) treatment. Because it causes the efflux of active metabolite, 5-fluoro- 2'deoxyuridine 5'-monophosphate [29]. ABC11 gene is also responsible for Methotrexate (MTA) resistance in breast cancer. Low expression levels of wild type $A B C 11$ causes the increase of MTA associated toxicity because of less MTA efflux out of the cell and increased accumulation [30].

\section{Conclusion}

Pharmacogenomics studies are very important for exploring the inherited genetic nature of the patient in disease conditions. The resultant differences in pharmacokinetic and pharmacodynamics parameters need to be optimized by appropriate drug discovery and providing a stronger scientific basis for optimizing drug therapy based upon each patient's genetic constitution. We need a rapid, accurate and costeffective technology to detect genetic variations in cancer patients. This will boost the clinical research in the context of pharmacogenomics and supports genotyping-based personalized medicine.

\section{References}

1. Shargel L, Andrew B, Wu-Pong S (2005) Applied biopharmaceutics and pharmacokinetics. McGraw-Hill, New York.

2. Gonzalez-Angulo AM, Hennessy BT, Mills GB (2010) Future of personalized medicine in oncology: A systems biology approach. J Clin Onco 28: 2777-2783.

3. Verma M (2012) Personalized medicine and cancer. J Pers Med 2: $1-14$

4. Zheng HY, Yan A, Xiong $H$ (2009) Personalized medicine for cancer Tumor. 29: 822-827.

5. Ananthula S (2014) Mechanisms mediating tocotrienol derivative in vitro and in vivo anticancer effects and inhibition of compensatory responses to hypoxia in the highly malignant mouse+ SA mammary cancer cells. University of Louisiana at Monroe.

6. Mamede AC, Tavares SD, Abrantes, Trindade J, Maia JM, et al. (2011) The role of vitamins in cancer: a review. Nutr Cancer 63: 479-494.

7. Anderson WF, Matsuno R (2006) Breast cancer heterogeneity: A mixture of at least two main types. J Natl Cancer Inst. 98: 948-951.

8. Bertucci F, Birnbaum D (2008) Reasons for breast cancer heterogeneity. J Biol 7: 6.

9. Jemal A, Bray F, Center MM, Ferlay F, Ward E, et al. (2011) Global cancer statistics. CA Cancer J Clin 61: 69-90.

10. Ananthula S, Parajuli P, Behery FA, Alayoubi AY, El-Sayed KA, et al. (2014) Oxazine derivatives of $\gamma$-and $\delta$-tocotrienol display enhanced anti-cancer activity in vivo Anticancer Res. 34: 2715-2726.

11. Peer D, Karp JM, Hong S, Farokhzad OC, Margalit R, et al. (2001) Nanocarriers as an emerging platform for cancer therapy. Nature Nanotechnology 2: 751-760.

12. Ananthula S, Parajuli P, Behery FA, Alayoubi AY, Nazzal S, et al. (2014) Tocotrienol oxazine derivative antagonizes mammary tumor cell compensatory response to $\mathrm{Cocl}_{2}$-induced hypoxia. Biomed Res Int.

13. Banerjee S, Kaye SB (2013) New strategies in the treatment of ovarian cancer: Current clinical perspectives and future potential. Clin Cancer Res 19: 961-968.

14. Ananthula S (2014) Bioavailability and bioequivalence issues associated with oral anticancer drugs and effect on drug market. J Bioequiv Availab 6: e56.

15. Ansari M, Krajinovic M (2007) Pharmacogenomics in cancer treatment defining genetic bases for inter-individual differences in responses to chemotherapy. Current Opinion in Pediatrics 19: 15-22.

16. Gout S, Huot J (2008) Role of cancer microenvironment in metastasis: focus on colon cancer. Cancer Microenviron 1: 69-83.

17. Witz IP (2009) The tumor microenvironment: The making of a paradigm. Cancer Microenviron 2: 9-17.

18. Ananthula S, Sinha A, El-Gassim M, Batth S, Marshall GD Jr, et al. (2016) Geminin overexpression-dependent recruitment and crosstalk with mesenchymal stem cells enhance aggressiveness in triple negative breast cancers. Oncotarget 7: 20869-2089. 
19. Morgan ET, Goralski KB, Piquette-Miller $M$, Renton KW, Robertson GR, et al. (2008) Regulation of drug-metabolizing enzymes and transporters in infection, inflammation and cancer, Drug Metab Dispos 36: 205-216.

20. Borges S, Desta Z, Li L, Skaar TC, Ward BA, et al. (2006) Quantitative effect of CYP2D6 genotype and inhibitors on tamoxifen metabolism: implication for optimization of breast cancer treatment. Clin Pharmacol Ther 80: 61-74.

21. Hoskins JM, Goldberg, Qu P, Ibrahim JP, McLeod HL (2007) UGT1A1*28 genotype and irinotecan-induced neutropenia: dose matters. J Natl Cancer Inst 99: 1290-1295.

22. Innocenti F, Undevia SD, Iyer L, Chen PX, Das S, et al. (2004) Genetic variants in the UDP-glucuronosyltransferase $1 \mathrm{~A} 1$ gene predict the risk of severe neutropenia of irinotecan. J Clin Oncol 22: $1382-1388$

23. Fisher B, Brown AM, Dimitrov NV, Poisson R, Redmond C, et al. (1990) Two months of doxorubicin-cyclophosphamide with and without interval reinduction therapy compared with 6 months of cyclophosphamide, methotrexate, and fluorouracil in positive-node breast cancer patients with tamoxifennonresponsive tumors: results from the National Surgical Adjuvant Breast and Bowel Project B-15. J Clin Oncol 8: 1483-1496.

24. Huang Z, Roy P, Waxman DJ (2000) Role of human liver microsomal CYP3A4 and CYP2B6 in catalyzing $\mathrm{N}$ - dechloroethylation of cyclophosphamide and ifosfamide. Biochem Pharmacol 59: 961-972.

25. Teng DH, Hu R, Lin H, Davis T, lliev D, et al. (1997) MMAC1/PTEN mutations in primary tumor specimens and tumor cell lines. Cancer Res 57: 5221-5225.

26. Nagata Y, Lan KH, Zhou X, Tan M, Esteva FJ, et al. (2004) PTEN activation contributes to tumor inhibition by trastuzumab, and loss of PTEN predicts trastuzumab resistance in patients. Cancer Cell 6: 117-127.

27. Kerb R, Hoffmeyer S, Brinkmann U (2001) ABC drug transporters: Hereditary polymorphisms and pharmacological impact in MDR1, MRP1 and MRP2, Pharmacogenomics 2: 51-64.

28. Toyoda $Y$, Ishikawa $T$ (2010) Pharmacogenomics of human $A B C$ transporter ABCC11 (MRP8): Potential risk of breast cancer and chemotherapy failure. Anticancer Agents Med Chem 10: 617-624.

29. Oguri T, Bessho Y, Achiwa H, Ozasa H, Maeno K, et al. (2007) MRP8/ABCC11 directly confers resistance to 5-fluorouracil. Mol Cancer Ther 6: 122-127.

30. Uemura $\mathrm{T}$, Oguri $\mathrm{T}$, Ozasa $\mathrm{H}$, Takakuwa $\mathrm{O}$, Miyazaki $\mathrm{M}$, et al. (2010) ABCC11/MRP8 confers pemetrexed resistance in lung cancer. Cancer Sci 101: 2404-2410. 